\title{
CONTINUOUS BIODIESEL PRODUCTION USING ULTRASOUND CLAMP ON TUBULAR REACTOR
}

\author{
Leong Boon Soon ${ }^{1}$, Anika Zafiah M. Rus ${ }^{* 2}$ and Sulaiman Hasan ${ }^{3}$ \\ ${ }^{1,2,3}$ Department of Materials and Design Engineering \\ Faculty of Mechanical and Manufacturing Engineering \\ Universiti Tun Hussein Onn Malaysia \\ 86400, Parit Raja, Batu Pahat, Johor, MALAYSIA \\ Email: ${ }^{1}$ bsoon86@yahoo.com, ${ }^{2}$ zafiah@uthm.edu.my, ${ }^{3}$ sulaiman@uthm.edu.my
}

\begin{abstract}
Biodiesel is an alternative fuel to replace diesel fuel for diesel engines. It consists of alkyl monoesters of fatty acid from vegetable oil or animal fats and it is an alternative feedstock that can be converted into biodiesel at lower cost. The approach of this production is to use the ultrasound clamp to better enable the immiscible liquids between the vegetable oil and alcohol to emulsify together, hence producing esters in a short period of time. The ultrasound causes the rapid movement of fluid, creating cavitation where the liquids break down and so forming cavitation bubbles. The optimum result for biodiesel production using an ultrasound clamp on the tubular reactor is 3 minutes with $90 \%$ conversion of esters, compared to the previous pilot plant unit which achieves $98 \%$ ester conversion within 5 minutes. The newly fabricated small pilot plant has proved able to achieve conversion of esters in the presence of a methanol to oil molar ratio of $12: 1$, catalyst concentration of $1.25 \mathrm{wt} \%$ and reaction temperature of $64^{\circ} \mathrm{C}$. This pilot plant has been developed in this research to facilitate the transesterification process in producing biodiesel from vegetable oil and has the ability to achieve $90 \%$ ester conversion with an ultrasound clamp.
\end{abstract}

Keywords: Alternative feedstock; fatty acid methyl ester; ultrasonic; transesterification; FTIR spectra.

\section{INTRODUCTION}

Biodiesel is an alternative diesel fuel that is derived from vegetable oils or animal fats through a process called transesterification. Biodiesel is mono-alkyl esters and plays an important role in the fuel landscape (Erhan et al., 2009). Biodiesel is competitive with petroleum products and has the advantages of reduced carbon emission, safer handling given its higher flash point compared to petrol-based products, and it is biodegradable (Rahim, Mamat, Taib\& Abdullah, 2012; Mat Yasin, Mamat, Sharma, \& Yusop, 2012). The biodiesel reaction requires a catalyst, either sodium hydroxide or potassium hydroxide, to split the oil molecules and alcohols such as methanol and ethanol to combine the separated esters (Leong, Rus, \& Hasan, 2013). From the reaction, glycerol is produced as the main by-product. Transesterification is widely used in industry to produce biodiesel as this process reduces the viscosity of the vegetable oil (Pinto et al., 2005; Ghobadian, Najafi, \& Nayebi, 2013). The stoichiometric ratio for the transesterification reaction requires three moles of alcohol and one mole of triglyceride to yield three moles of fatty acid ester and one mole of glycerol. A higher molar ratio will eventually lead to greater esters production in a shorter time. Transesterification is a 
general term where the ester is transformed into another through the interchange of the alkoxy moiety as the ester reacts with the alcohol, and transesterification, also called alcoholysis, takes place (Schuchardt et al., 2008). However, the most important variables which affect the production of biodiesel are the methanol to oil molar ratio and the reaction temperature.

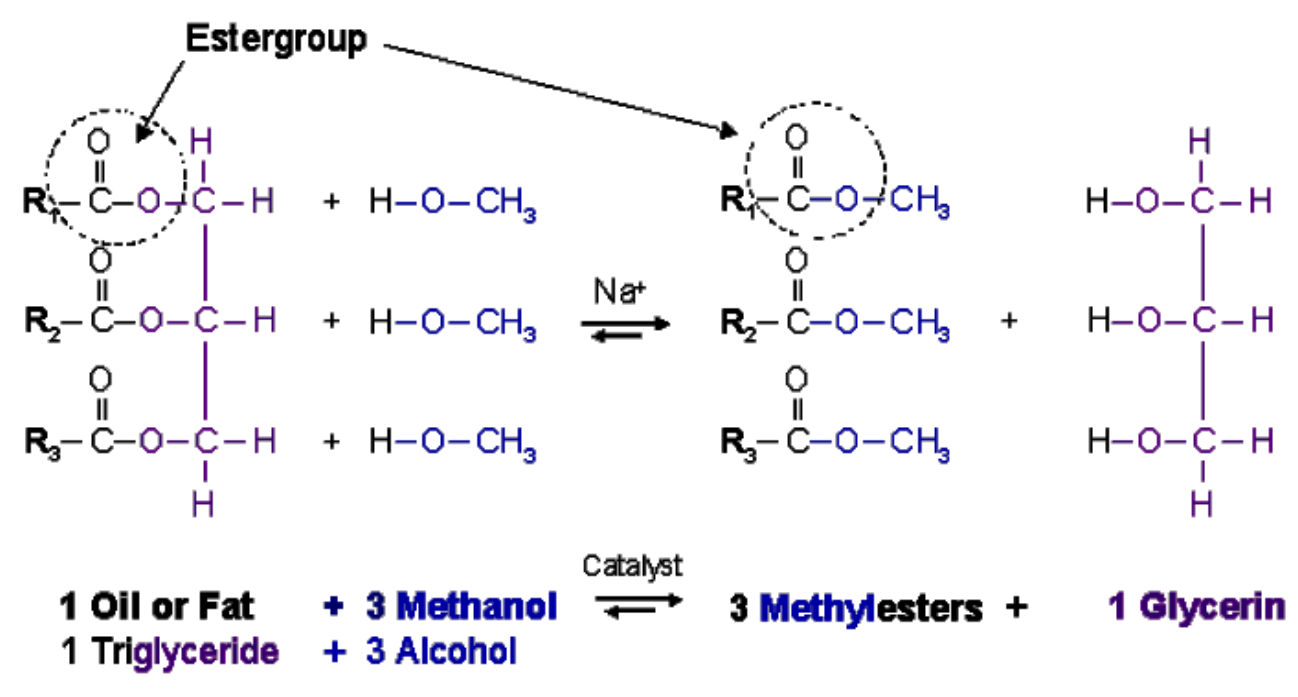

Figure 1. Transesterification of triglycerides in the presence of methanol where three moles of alcohol and one mole of triglyceride yield three moles of fatty acid esters and one mole of glycerol (Demirbas, 2008).

The transesterification reaction will proceed well in the presence of homogeneous catalysts such as potassium hydroxide $(\mathrm{KOH})$, sodium hydroxide $(\mathrm{NaOH})$ and sulfuric acid $\left(\mathrm{H}_{2} \mathrm{SO}_{4}\right)$ or with heterogeneous catalysts such as metal oxides or carbonates. In the industry, the most commonly used catalyst in the production of biodiesel is sodium hydroxide, commonly called lye. This is because sodium hydroxide is low in cost and the reaction it causes as catalyst produces a higher yield (Demirbas, 2003). In addition, the viscosity of vegetable oil can be reduced by using other methods, namely blending pyrolysis, microemulsification and transesterification (Ma, Clements, \& Hanna, 1998). Highly viscous vegetable oil will eventually cause severe operational problems such as engine deposits (Knothe \& Dunn, 2001). In the transesterification process, the acid value of the vegetable oil should be less than $1 \%$ and all materials should be substantially anhydrous. The esterification process may be required if there is more than $1 \%$, so more sodium hydroxide or potassium hydroxide is needed to neutralize the free fatty acids. It can also be observed that water causes the formation of soap and frothing increases the viscosity of the biodiesel (Demirbas, 2003). Water which is present during the transesterification reaction will lead to soap formation, which consumes the catalyst and eventually reduces the effectiveness of the catalyst and reduces the yield of methyl ester. Besides that, the catalyst concentration has a significant effect during the transesterification reaction (Leong et al., 2013).

The conventional stirring method in biodiesel production has low rates of chemical reaction, leading to longer production time (Leong et al., 2013). The use of ultrasonics in the transesterification reaction helps to increase the yield of biodiesel production. Oil and methanol are not completely miscible in biodiesel processing and 
the assistance of ultrasonics is an effective method that helps to achieve a better mixing and enhancement of the liquid-liquid mass transfer (Ji et al., 2006). From the research, the results show that the ultrasonics produces smaller droplets than with standard mixing.
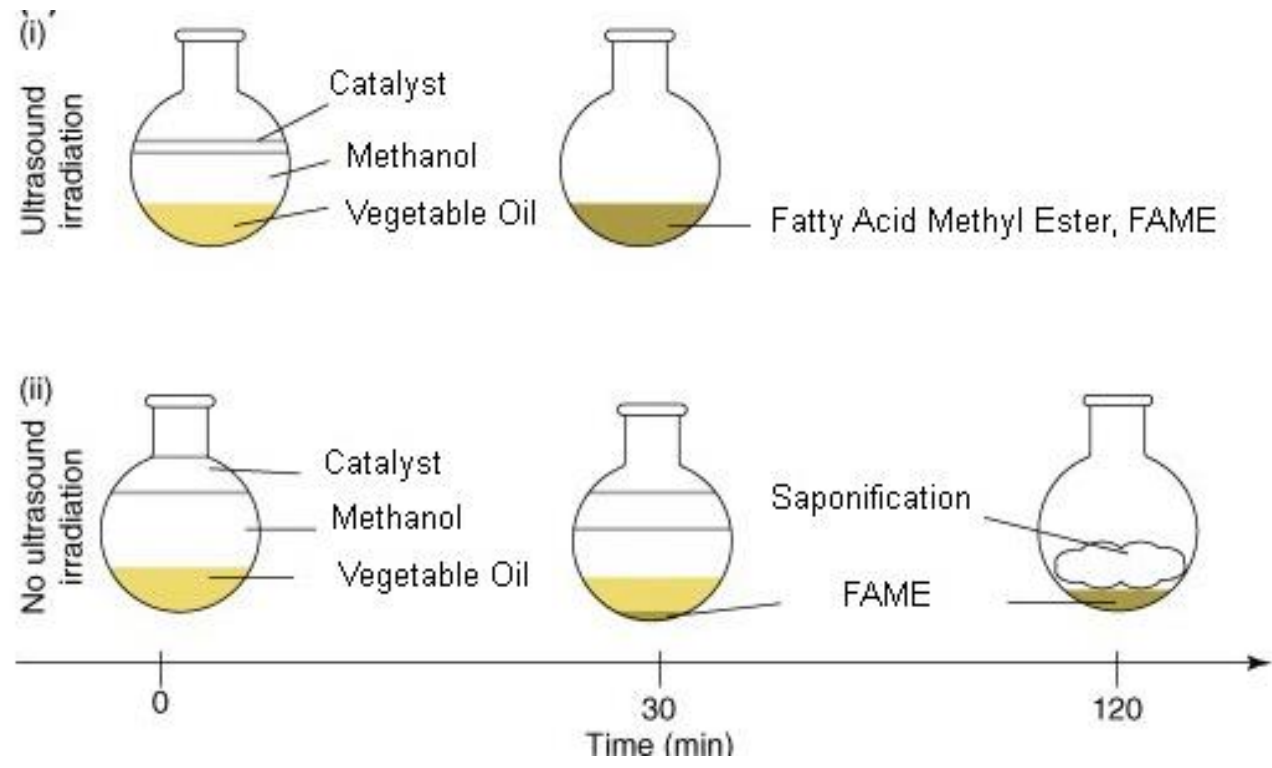

Figure 2. Biofuel production and process monitoring of ultrasound-assisted process and non-ultrasound-assisted process in determining the yield of FAME (Rokhina et al., 2009).

Ultrasonic irradiation of liquids causes two immiscible liquids to emulsify as a result of the generated shockwaves which disrupt and interfere with the phase boundary, causing emulsification to take place. The cavitation bubbles have a variety of effects within the liquid medium depending upon the type of system in which it is generated (Leong et al., 2013). These systems can be broadly divided into homogeneous liquid, heterogeneous solid/liquid and heterogeneous liquid/liquid. Within chemical systems, these three groupings represent most processing situations. When sound waves propagate through a liquid medium, they generate compression and rarefaction regions in the liquid. The intermolecular distances between the liquid molecules also expand and contract along these waves. At very low pressure in the rarefaction region, the intermolecular spaces exceed the critical molecular distance and the liquid tears apart to form void spaces or micro bubbles. These micro bubbles oscillate with the wave motion and grow in size by taking in vapour from the surrounding liquid medium and by aggregating with other micro bubbles (Mason, 1999). By using ultrasonics, the reaction time was found to be much shorter (10 to $40 \mathrm{~min}$ ) than with the mechanical stirring method, hence improving the conversion rate of esters (Hanh et al., 2009).

\section{EXPERIMENTAL METHOD}

Edible vegetable oil was purchased at a grocery stall near Parit Raja. Methanol $\left(\mathrm{CH}_{3} \mathrm{OH}\right)$, sodium hydroxide $(\mathrm{NaOH})$ and $\mathrm{HmbG}$ potassium hydroxide $(\mathrm{KOH})$ with 99\% purity were purchased from the chemical supplier. Other chemicals such as anhydrous sodium sulfate $\left(\mathrm{Na}_{2} \mathrm{SO}_{4}\right)$, magnesium sulfate $\left(\mathrm{MgSO}_{4}\right)$, and sulfuric acid $\left(\mathrm{H}_{2} \mathrm{SO}_{4}\right) 99 \%$ purity were also obtained from another chemical supplier. The optimum 
parameters from the transesterification process were used to produce a small biodiesel ultrasonic process plant (BUPP) with the assistance of an ultrasound clamp on a tubular reactor. For preliminary lab scale production of biodiesel, the ultrasound clamp with tubular reactor was used to enhance the emulsification process of the edible vegetable oil and methanol. The acid value was determined by the AOCS Ca5a-40 method to estimate the free fatty acid content in the edible vegetable oil. The ultrasonic frequency was applied at $20 \mathrm{kHz}$ with methanol to oil molar ratios of $6: 1,9: 1$ and 12:1 respectively. For a homogeneous transesterification reaction, $250 \mathrm{~mL}$ of vegetable oil was heated at $64^{\circ} \mathrm{C}$ and fed into the tubular reactor with the presence of different catalyst concentration amounts of $0.75 \%, 1.00 \%$ and $1.25 \%$. The tubular reactor was then clamped with the ultrasonic clamp and emulsification through the ultrasound clamp on the tubular reactor for 1 minute began. The ultrasonic tubular reactor model MSG.1200.IX-LF was used to perform the transesterification reaction in which vegetable oil, methanol and catalyst were emulsified in the tubular reactor with the assistance of the ultrasound clamp on the tubular reactor. The ultrasonic tubular reactor has a diameter of $21 \mathrm{~mm}$ diameter $\times 600 \mathrm{~mm}$ in length with quick flanges and covers made of stainless steel (SS316L). The equipment comes with an ultrasonic clamp on the tubular reactor, generator, ultrasonic converter/ transducer and computer control. The ultrasonic system uses a unique multi-frequency multimode (MMM) and modulated technology which delivers high power ultrasonic energy to the mixture to form acoustic cavitations and to achieve a higher yield of biodiesel production.

Table 1. Specification of ultrasonic clamp on tubular reactor.

\begin{tabular}{ll}
\hline \multicolumn{1}{c}{ Technical Characteristic } & \multicolumn{1}{c}{ MSG.1200.IX-LF } \\
\hline Main supply voltage & $220 / 230 \mathrm{~V} ; 50 / 60 \mathrm{~Hz}$ \\
Max. input power & $1300 \mathrm{~W}$ \\
Non-modulated, carrier frequency & $17.5 \mathrm{kHz}-28.5 \mathrm{kHz}$ \\
range & \\
Modulated acoustic frequency range & Wideband from Hz to MHz \\
Average continuous output power & $1200 \mathrm{~W}$ \\
Peak output (max. pulse power) & $6000 \mathrm{~W}$ \\
Output HF voltage & $500 \mathrm{~V}$ \\
Weight & $10 \mathrm{~kg}$ \\
\hline
\end{tabular}

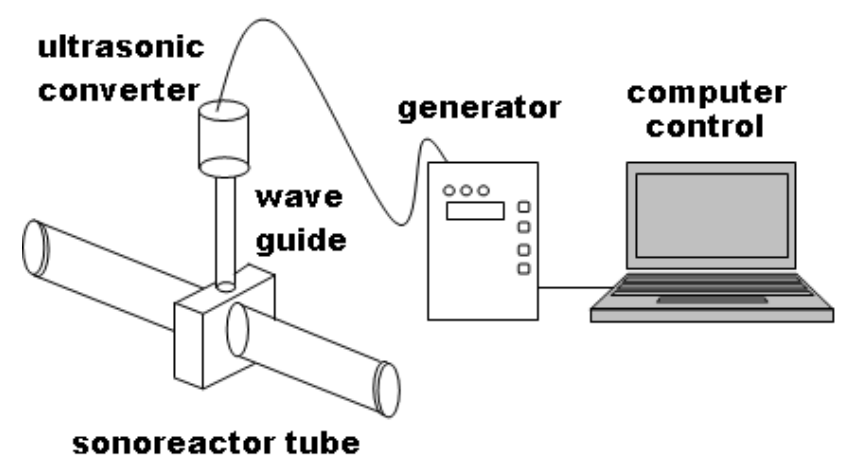

Figure 3. Schematic of ultrasonic clamp on tubular reactor during the biodiesel production using an ultrasonic converter, wave guide, generator and computer controller system to monitor the frequency (Leong et al., 2013). 
After the reaction, glycerol was separated using a separating funnel, and the methyl ester was cleaned to remove excess alkali, methanol and water. The purified methyl ester or biodiesel was measured for viscosity using a Viscolite 700, density and Fourier transform infrared spectroscopy (FTIR).

\section{RESULTS AND DISCUSSION}

Based on the result obtained, according to Figure 5, the highest FAME yield using the ultrasound clamp on the tubular reactor was $96 \%$ with a methanol to oil molar ratio of 9:1 and catalyst concentration of $0.75 \mathrm{wt} \%$, followed by the $1.00 \mathrm{wt} \%$ catalyst concentration with the same molar ratio. From the research undertaken, it can be observed that the yield of esters is affected by the ratio of methanol used, as reported by other researchers (Meher, Dharmagadda, \& Naik, 2006). To achieve a high yield of ester, alcohol has to be used in excess, such that the transesterification reaction is a process of changing the alkoxy group of an ester compound by another alcohol. The time for ultrasonication which takes place in the tubular reactor was 1 minute. A longer ultrasonication time will cause a decrease of the esters, as the emulsion that forms will trap some esters. According to other researchers, a higher frequency will cause the cavitation bubbles to become too weak to impinge one liquid to the other (Stavarache et al., 2005). A low FAME yield was recorded at $85 \%$ with a methanol to oil molar ratio of 6:1 and catalyst concentration of $1.25 \mathrm{wt} \%$.

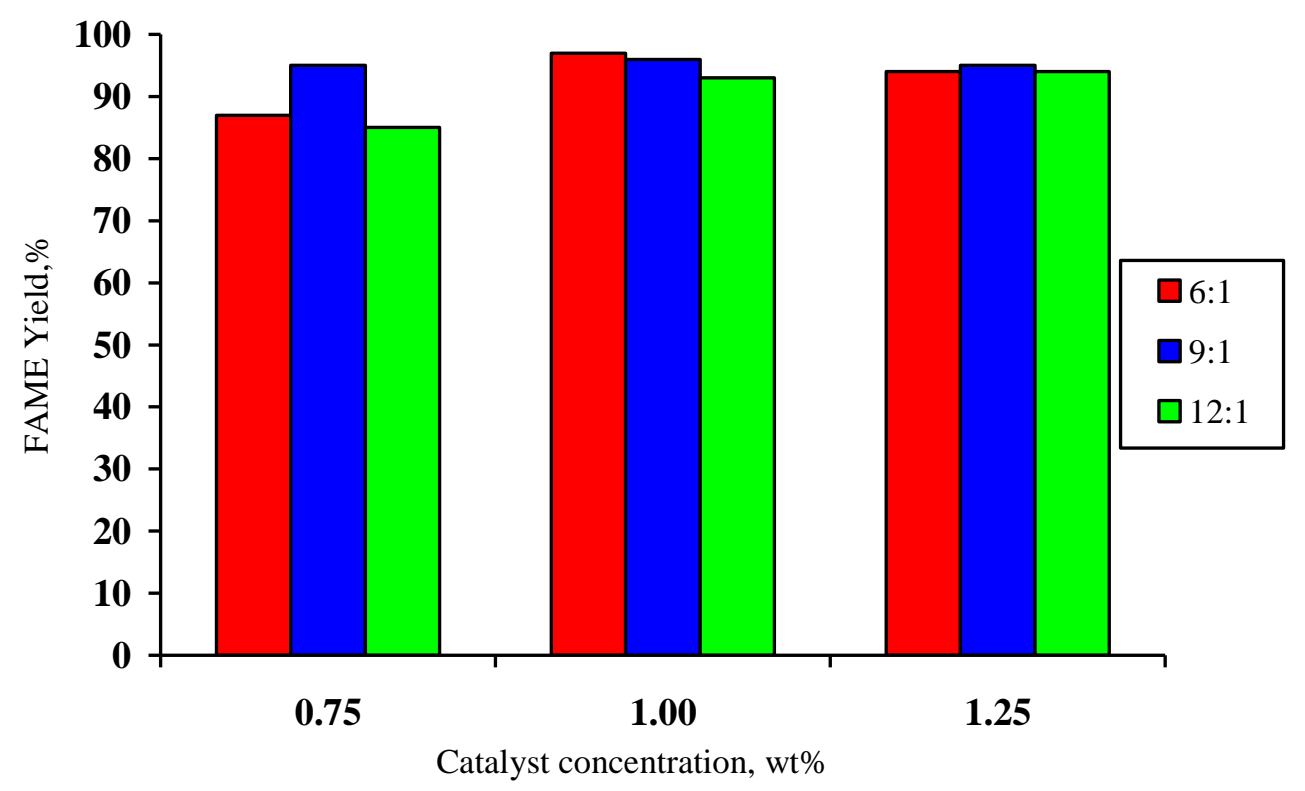

Figure 4. Results of fatty acid methyl ester (FAME) yield with the comparison towards the catalyst concentration and molar ratio.

The low FAME yield may be caused by the low volume of biodiesel retrieved at the end of the transesterification process. As an example, separating and washing of the biodiesel reduces the amount of biodiesel due to human error. To eliminate these problems, better equipment such as the use of vacuum filtration can help to reduce losses which might be caused by overexposure to the atmosphere which also contains moisture. High moisture content will eventually become a tremendous drawback when 
converting the vegetable oil into biodiesel. According to Jo Han $\mathrm{Ng}$, esters reduction is caused by the increase of free fatty acid (FFA) content or moisture content during the washing process, leading to soap formation ( $\mathrm{Ng}$ et al., 2009). Besides that, the low biodiesel yield from the ratio 6:1 with catalyst concentrations of $0.75 \mathrm{wt} \%$ and 1.25 wt $\%$ may be caused by incomplete reaction during the transesterification process, in which the triglyceride, diaglyceride and monoglyceride were not fully converted into esters.

\begin{tabular}{cccccc}
\multicolumn{5}{c}{ Table 2. Kinematic viscosity values at $40^{\circ} \mathrm{C},\left(\mathrm{mm}^{2} / \mathrm{s}\right)$} \\
\hline \multirow{2}{*}{ M: O } & $\begin{array}{c}\text { Catalyst concentration } \\
(\mathrm{wt} \%)\end{array}$ & $\begin{array}{c}\text { Sample } 1 \\
\left(\mathrm{~mm}^{2} / \mathrm{s}\right)\end{array}$ & $\begin{array}{c}\text { Sample } 2 \\
\left(\mathrm{~mm}^{2} / \mathrm{s}\right)\end{array}$ & $\begin{array}{c}\text { Sample 3 } \\
\left(\mathrm{mm}^{2} / \mathrm{s}\right)\end{array}$ & $\begin{array}{c}\text { Average } \\
\left(\mathrm{mm}^{2} / \mathrm{s}\right)\end{array}$ \\
\hline \multirow{3}{*}{$6: 1$} & 0.75 & 3.7 & 3.8 & 3.4 & 3.6 \\
& 1.00 & 3.7 & 3.8 & 3.6 & 3.7 \\
& 1.25 & 3.7 & 3.5 & 3.6 & 3.6 \\
$9: 1$ & 0.75 & 3.5 & 3.8 & 3.7 & 3.6 \\
& 1.00 & 3.5 & 3.5 & 3.9 & 3.6 \\
$12: 1$ & 1.25 & 3.5 & 3.8 & 3.5 & 3.6 \\
& 0.75 & 3.5 & 3.9 & 3.8 & 3.7 \\
& 1.00 & 3.9 & 3.3 & 3.8 & 3.7 \\
& 1.25 & 3.9 & 3.8 & 3.7 & 3.8 \\
\hline
\end{tabular}

Based on Table 2, the kinematic viscosity is tested at a temperature of $40^{\circ} \mathrm{C}$. According to Knothe, high kinematic viscosities of vegetable oil will cause engine deposits if it is used directly as fuel (Knothe et al., 2005). The table shows that the kinematic viscosity for the samples ranges from $2.6 \mathrm{~mm}^{2} / \mathrm{s}$ to $3.8 \mathrm{~mm}^{2} / \mathrm{s}$. According to the EN14214 standard, biodiesel's kinematic viscosity ranges from $3.5 \mathrm{~mm}^{2} / \mathrm{s}$ to 5.0 $\mathrm{mm}^{2} / \mathrm{s}$ and, according to ASTM D6751, it is $1.9 \mathrm{~mm}^{2} / \mathrm{s}$ to $4.1 \mathrm{~mm}^{2} / \mathrm{s}$. Theoretically, the kinematic viscosity will decrease when the temperature increases, meaning that heat is present or being supplied. High viscosity would cause poor combustion and increased exhaust smoke if the biodiesel were to be run in a diesel engine. In addition, high kinematic viscosity of biodiesel makes the biodiesel unable to flow freely and steadily in the engine system, leading to engine failure due to its low fluidity. However, low kinematic viscosity causes the lubricant layer on the inner wall of the engine to wear. This is because biodiesel is unable to compensate the loss of lubricant due to its high fluidity, hence making it difficult to adhere to and cover the wall of the engine system. According to the ASTM D6751 and EN 14214 standards, the biodiesel produced from this research meets but does not exceed the kinematic viscosity values, meaning that the sample values are in the acceptable range.

The density of biodiesel is determined from the contents of the ester, where the ester's density is determined from the oil from which it originates as taken during the transesterification process. For a methanol to oil molar ratio of 9:1 with catalyst concentration of $1 \mathrm{wt} \%$, the density obtained was $914 \mathrm{~kg} / \mathrm{m}^{3}$, which is higher than the EN 14214 standard, which limits the biodiesel density to a range from $860 \mathrm{~kg} / \mathrm{m}^{3}$ to 900 $\mathrm{kg} / \mathrm{m}^{3}$. The high value of the biodiesel density may be caused by the presence of water content and FFA composition. The density of biodiesel is caused by a conversion factor which will eventually affect the density value (Knothe et al., 2005). The low conversion of the biodiesel leads to the presence of methanol and water content within the biodiesel (Knothe et al., 2005). However, the density of the biodiesel decreases proportionally depending on the molar ratio and catalyst concentration being used. 
Table 3. Density of FAME at $15^{\circ} \mathrm{C}$ with different molar ratio and catalyst concentrations

\begin{tabular}{ccc}
\hline M:O & Catalyst concentration $(\mathrm{w} / \mathrm{w} \%)$ & Density $\left(\mathrm{kg} / \mathrm{m}^{3}\right)$ \\
\hline \multirow{2}{*}{$6: 1$} & 0.75 & 905 \\
& 1.00 & 899 \\
& 1.25 & 884 \\
$9: 1$ & 0.75 & 893 \\
& 1.00 & 914 \\
\multirow{2}{*}{$12: 1$} & 1.25 & 902 \\
& 0.75 & 889 \\
& 1.00 & 896 \\
\end{tabular}

The FTIR analysis was conducted to observe the formation of the functional group that exists from the FAME. Figure 6 below shows the results of the functional group where ester was formed during the transesterification reaction. The intensity was strong, as the characteristic absorptions were at $1743.96 \mathrm{~cm}^{-1}$, showing that the ester $\mathrm{C}=\mathrm{O}$ is in the range of 1735 to 1750 . The FTIR models are based on the concentration of the chemical groups in the FAME. The FTIR spectra of biodiesel are expected to be very similar to oil, since the compound has almost the same chemical groups. However, some slight differences can be detected, such as the fact that the carbonyl band position in FTIR is sensitive to the substituent effects and to the structure of the molecule itself (Pasto, Johnson, \& Miller, 1992).

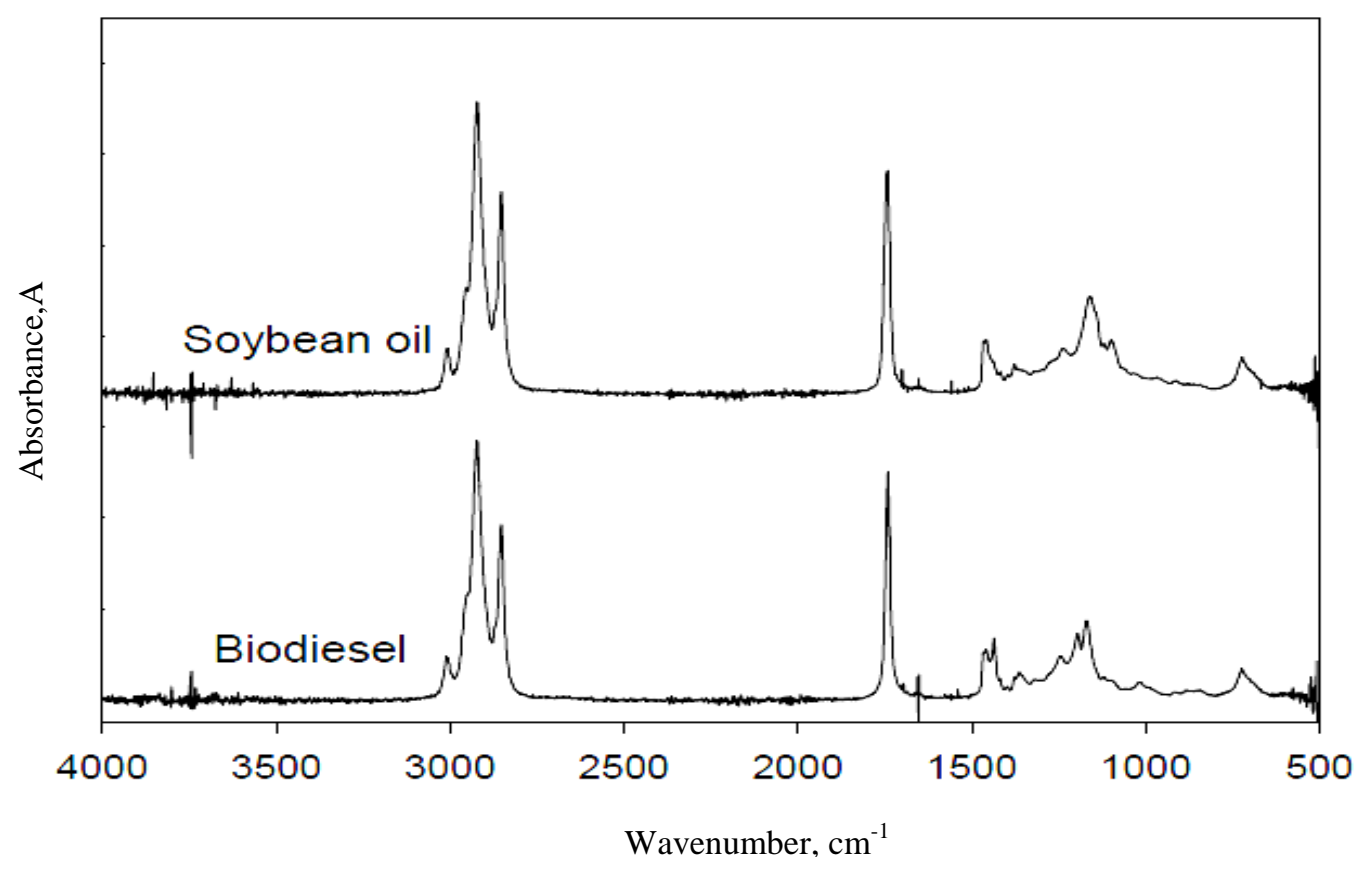

Figure 5. Comparison of FTIR spectra of soybean oil and biodiesel, showing that the formation of esters is quite similar in biodiesel production (Pedroso et al., 2005) 


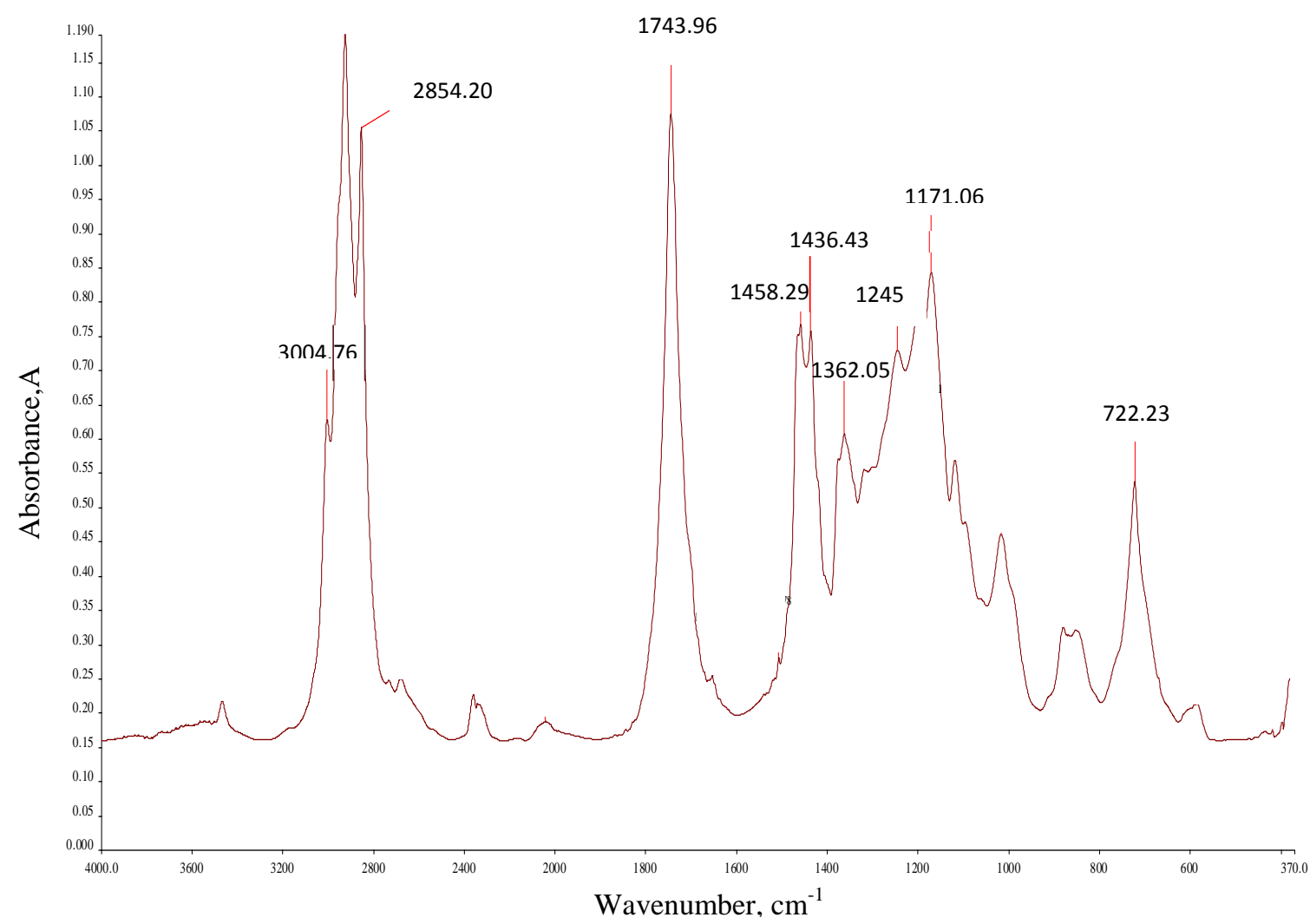

Figure 6. FTIR spectra analysis of fatty acid methyl ester with a methanol to oil molar ratio of 9:1 and catalyst concentration of $0.75 \mathrm{wt} \%$.

\section{CONCLUSION}

In conclusion, biodiesel can be produced by using an ultrasonic clamp on a tubular reactor, an equipment setup that enhances the production of biodiesel. The resulting product is within the limits of the ASTM D6751 and EN 14214 standards. This method using an ultrasound clamp can reduce the transesterification reaction time such that it has the ability to produce a FAME yield of $90 \%$ in 1 minute. The use of ultrasonic energy is indeed a valuable tool for the transesterification of vegetable oil to biodiesel, and this method is far better than the conventional stirring method.

\section{ACKNOWLEDGMENT}

The authors would like to thank the Malaysian Government, University Tun Hussein Onn Malaysia (UTHM), Johor and all who have contributed to making this research a success under the Prototype Research Grant Scheme (PRGS) Vot 0903, Malaysian Technical University Centre of Excellence (MTUN CoE) research grant Vot C014 and Vot $\mathrm{C} 015$ for their contribution in various ways.

\section{REFERENCES}

Demirbas, A. (2008). Biodiesel: a realistic fuel alternative for diesel engines. London: Springer Verlag. 
Demirbas, A. (2003). Biodiesel fuels from vegetable oils via catalytic and non-catalytic super critical alcohol transesterifications and other methods: a survey. Energy Conversion and Management, 44, 2093-2109.

Erhan, S. Z., Dunn, R. O., Knothe, G., \& Moser, B. R. (2009). Fuel properties and performance of biodiesel. Food and Industrial Oils Research Unit, U.S. Department of Agriculture, Agricultural Research Service, National Center for Agricultural Utilization Research, Peoria, IL.

Ghobadian, B., Najafi, G., \& Nayebi, M. (2013). A semi-empirical model to predict diesel engine combustion parameters. Journal of Mechanical Engineering and Sciences, 4, 373-382. Hanh, H. D., Dong, N. T., Okitsu, K., Nishimura, R., \& Maeda, Y. (2009). Biodiesel production through transesterification of triolein with various alcohols in ultrasonic field. Renewable Energy, 34, 766-768.

Ji, J., Wang, J., Li, Y., Yu, Y., \& Xu, Z. (2006). Preparation of biodiesel with the help of ultrasonic and hydrodynamic cavitation. Ultrasonics, 44, e411- e414.

Knothe, G. \& Steidley, K. R. (2005). Kinematic viscosity of biodiesel fuel components and related compounds. Influence of compound structure and comparison to petrodiesel fuel components. Fuel, 84, 1059-1065.

Knothe, G. \& Dunn, R. O. (2001). Biofuels derived from vegetable oils and fats. In Oleochemical manufacture and applications (pp. 106-163). Sheffield Academic Press.

Knothe, G., Van Gerpen, J. H., \& Krahl, J. (2005). The biodiesel handbook. AOCS Press: Champaign, IL.

Leong, B. S, Rus, A. Z. M., \& Hasan, S. (2013). The novel continuous biodiesel process using ultrasonic clamp on tubular reactor. Applied Mechanics and Materials, 315, 691-694.

Ma, F., Clements, L. D., \& Hanna, M. A. (1998). The effects of catalyst free fatty acids and water on transesterification of beef tallow. Transactions of the American Society of Agricultural Engineers, 41, 1261-1264.

Mason, T. J. (1999). Sonochemistry. New York: Oxford University Press.

Mat Yasin, M. H., Mamat, R., Sharma, K. V., \& Yusop, A. F. (2012). Influence of palm methyl ester (PME) as an alternative fuel in the multicylinder diesel engine. Journal of Mechanical Engineering and Sciences, 3, 331-339.

Meher, L. C., Dharmagadda, V. S. S., \& Naik, S. N. (2006). Optimization of alkali catalyzed transesterification of Pongamia pinnata oil for production of biodiesel. Bioresource Technology, 97, 1392-1397.

Ng, J. H., Ng, H. K., Jourabchi, S. A., \& You, C. M. (2009). A novel steady state test cycle for emissions characterization of a light duty diesel engine fuelled with biodiesel. Proceedings of the 2009 International Conference on Chemical, Biological and Environmental Engineering, 9-11 Oct., Singapore.

Pasto, D., Johnson, C., \& Miller, M. (1992). Experiments and techniques in organic chemistry. New Jersey: Prentice Hall.

Pedroso, L. M., Ferreira, J. L., Falcao, J., Simoes, P. N., Simao, A. V., \& Portugal, A. (2005). Biodiesel - "alternative fuel". In Proceedings of the 9th International Chemical Engineering Conference (CHEMPOR 2005), Coimbra, Setembro.

Pinto, A. C., Guaririro, L. L. N., Rezende, M. J. C., Ribeiro, N. M., Torres, E. A., Lopes, W. A., Pereira, P. A. P., \& de Andrade, J. B. (2005). Biodiesel: an overview. Journal of the Brazilian Chemical Society, 16, 1313-1330. 
Rahim, R. Mamat, R., Taib, M. Y., \& Abdullah, A. A. (2012). Influence of fuel temperature on a diesel engine performance operating with biodiesel blended. Journal of Mechanical Engineering and Sciences, 2, 226-236.

Rokhina, E. V., Lens, P., \& Virkutyte, J. (2009). Low frequency ultrasound in biotechnology: state of the art. Trends in Biotechnology, 27(5), 298-306.

Schuchardt, U., Sercheli, R., \& Vargas, R. M. (2008). Transesterification of vegetable oils: a review. Journal of the Brazilian Chemical Society, 9, 199-210.

Stavarache, C., Vinatoru, M., Nishimura, R., \& Maeda, Y. (2005). Fatty acids methyl esters from vegetable oil by means of ultrasonic energy. Ultrasonics Sonochemistry, 12, 367-372. 